\title{
Antioxidants and carbohydrate content in infusions and microwave extracts from eight medicinal plants
}

\author{
Nadezhda Petkova*, Lili Ivanova, Gerasima Filova, Ivan Ivanov, Panteley Denev \\ Department of Organic Chemistry and Inorganic Chemistry, University of Food Technologies, Plovdiv, Bulgaria.
}

\begin{tabular}{|c|c|}
\hline ARTICLE INFO & ABSTRACT \\
\hline Article history: & \multirow{11}{*}{ 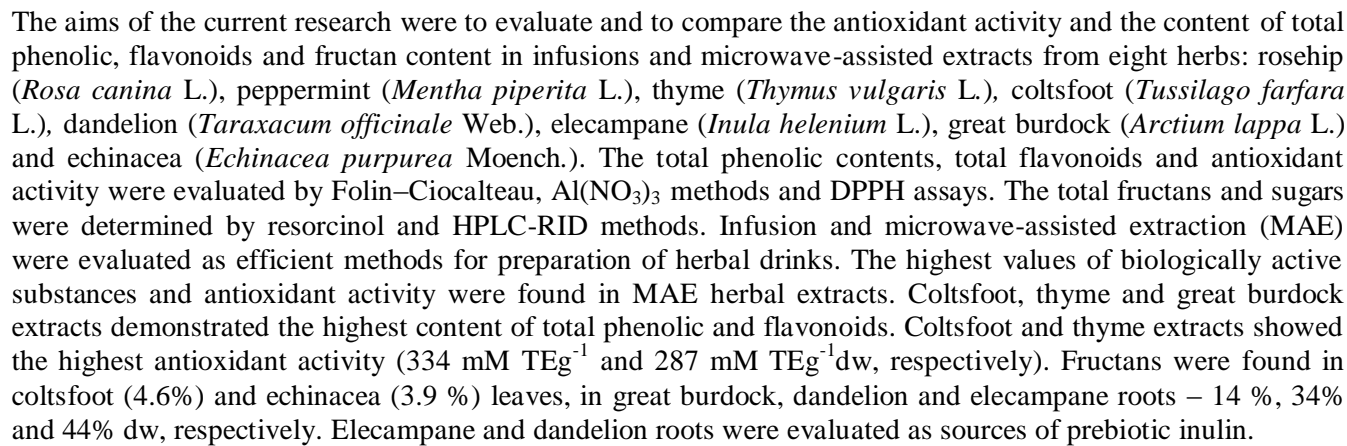 } \\
\hline Received on: 19/06/2017 & \\
\hline$/ 08 / 2017$ & \\
\hline Available on & \\
\hline Key words: & \\
\hline Medicinal plants, phenolic & \\
\hline compounds, antioxidant & \\
\hline activity, inulin. & \\
\hline & \\
\hline & \\
\hline & \\
\hline
\end{tabular}

\section{INTRODUCTION}

Medicinal plants present a rich source of bioactive compounds and antioxidants with significant importance in human health. Herbs find application in many fields, including medicine, nutrition, flavouring, beverages, dyeing, repellents, fragrances, cosmetics (Djeridane et al., 2006). Crude extracts of herbs and spices, rich in phenolics are of increasing interest in the food industry because they improve the quality and nutritional value of food (Wojdyło et al., 2007). In addition, consumption of herbal infusions increased all over the world due to the beneficial and preventive effect over human body.

\footnotetext{
* Corresponding Author Nadezhda Petkova, AffiliationDepartment of Organic Chemistry and Inorganic Chemistry, University of Food Technologies, 26 Maritza Blvd., 4002, Plovdiv, Bulgaria. E-mail: petkovanadejda @ abv.bg; Tel: +359888840789; Fax: +35932644102
}

The quality of herbal drug is also depend on many factors like environment, collection method, cultivation, harvest, postharvest processing, transport and storage practices (Kunle et al., 2012). Therefore, the great variety of herbs used for preparation of herbal infusions requires monitoring and analysis of final beverages. Rosehip, peppermint, thyme infusions are the mostly consumed herbal infusions. In Bulgarian folk medicine rosehip, peppermint, thyme, coltsfoot and elecampane are traditionally used for curing respiratory disorders (Pamukov and Ahtardjiev, 1990). Peppermint leavers, great burdock and dandelion roots enhance digestion and kidney function (Pamukov and Ahtardjiev, 1990, Pawlaczyk et al., 2009, Krachanova et al., 2010). The detailed information is summarized in Table 1. Many studies were dedicated to biological activity of rosehip fruits (Ognyanov et al., 2014, Mihaylova et al., 2015, Taneva et al., 2016), thyme (Thymus vulgaris L.) and peppermint (Ivanova et al., 2005, Kolaneva et al., 2016). Common thyme is an aromatic plant that belongs to Lamiaceae family. Thyme has been employed in medicine, food, agriculture, veterinary and pest control (Ghahfarokhiet al., 2016). 
Table 1: Application of medicinal plants in phytotherapy and traditional medicine (Pamukov and Ahtardjiev, 1990; Barnes et al., 2005, Pawlaczyk et al., 2009, Krachanova et al., 2010).

\begin{tabular}{|c|c|c|c|}
\hline Common name & Family & Vegetal part & Traditional use \\
\hline RosehipRosa canina L. & Rosacea & fruits & In vitamin C- deficiency diseases, anti-flu, diuretic, cardiotonic \\
\hline Peppermint Mentha piperita L. & Labiatae & leaves & Spasmolytic, antiseptic, gastric disorders, indigestion neuralgia, myalgia, antivomiting \\
\hline Thyme Thymus vulgarisL. & Labiatae & Aerial parts & $\begin{array}{l}\text { Expectorant, antitusive, asthma, whooping-cough, insomnia, headache, anemia, } \\
\text { gastritis, colics, diarrhea }\end{array}$ \\
\hline Coltsfoots Tussilago farfara $\mathrm{L}$. & Asteraceae & leaves & $\begin{array}{l}\text { Gastrointestinal and urinary ailments, asthma, bronchitis, blood purification, } \\
\text { rheumatism and skin irritations }\end{array}$ \\
\hline Dandelion Taraxacum officinale Web. & Asteraceae & roots & $\begin{array}{l}\text { Cholagogue, diuretic, arthritis, antihepatic, antidiabetic, prevention of renal gravel and } \\
\text { loss of appetite }\end{array}$ \\
\hline Elecampane Inula helenium L. & Asteraceae & roots & Cholagogue, diuretic, antihelmintic, expectorant, wounds healing \\
\hline Great burdock Arctium lappa L. & Asteraceae & roots & Diuretic, rheumatism, gastritis, gout, throat pain, arthritis, rashes \\
\hline Echinacea Echinacea purpurea Moench & Asteraceae & leaves & Urinary diseases, curing syphilis and septic wounds, "anti-toxin"' for snakebites \\
\hline
\end{tabular}

Its anti-MRSA activity was also demonstrated (Khadir et al., 2013). Herbal infusion of peppermint (Mentha piperita) leaves helps in curing indigestion, jaundice, liver diseases and gastric disorders. It was reported that the flavonoids and phenolic acids in Mentha piperita exhibited antioxidant, cholegogic and anti-allergic activities (Ivanova et al., 2005, Krachanova et al., 2010).

Coltsfoot, dandelion, elecampane, great burdock and echinacea are medicinal plants from Asteraceae family. Coltsfoot has been used in folk remedies as herbal tea. The coltsfoot's pharmacological properties includes also antibacterial, antiinflammatory, antioxidant and also some neuroprotective activities (Nedelcheva et al., 2015).

In Bulgarian traditional herbal medicine dandelion is used mainly for treatment of digestive diseases. Its roots are a rich source of polysaccharides, mainly inulin-type fructans and smaller amounts of pectin, resin, and mucilage (Schütz et al., 2006, Petkova et al., 2015)

Arctium lappa L. possesses antioxidants and antidiabetic, anti-inflammatory effects, anti-cancers, anti-allergic effect, antiulcer effect, antitubercular activity, anti-acne, anti-sterility, antiulcerogenic, ulcerative colitis, angiostrongyliasis effect, gastroprotective activity, hepatoprotective effects, anti-aging effect, anti-austeric activity and cytotoxicity effect (Miraj and Keivani, 2016). Elecampane roots are used in folk medicine as infusions and tinctures for curing asthma, bronchitis, lung disorders, tuberculosis, indigestion, chronic enterogastritis, for wound healing, treatment of emesis and diarrhea. Its pharmacological properties include also anti-inflammatory, antioxidant, anticoagulant, anti-tumor, antimicrobial and insecticidal activities (Konishi et al., 2002, Stojakowska et al., 2006, Huo et al., 2008). Echinacea purpurea possesses important immuno-stimulatory and anti-inflammatory properties. The plant extracts have shown antioxidative, antibacterial, antiviral, and antifungal properties and are used for treating common cold and respiratory and urinary diseases (Barnes et al., 2005, Manayi et al., 2015). The aerial parts of echinacea contain alkamides, caffeic acid esters, polysaccharides and polyacetylenes (Barnes et al., 2005).

Most of the researches presented data about antioxidant activity and bioactive compounds obtained after $80 \%$ methanol, ethanol or acetone extraction (Ivanova et al., 2005; Krachanova et al., 2010, Petkova et al., 2017). These values did not present correctly the content because of its toxicity or limited used as a tincture. The quality of herbal drug is also depended on many factors like environment, collection method, cultivation, harvest, post harvest processing,transport, storage practices,technique, solvents, time and extraction temperature.

The most commonly used herbal extracts for oral intake are some herbal infusions. Nowadays, people applied microwave irradiation for preparation of herbal extracts in domestic ovens. Therefore, the comparison of extraction of phytochemical compounds obtained by MAE and infusion presents interest for the consumers.

The aim of the current study was to evaluate the content of biologically active compounds (phenolic, flavonoids and fructans) and antioxidant activity of the water extracts form eight medicinal plants rosehip fruits, elecampane roots, dandelion roots, great burdock roots, thyme, coltsfoot, peppermint leaves obtained by infusion and microwave-assisted extraction.

\section{MATERIALS AND METHODS}

\section{Plant material}

The plant material was purchased from the local drugstore in Plovdiv, Bulgaria. The dried and coarsely ground roots of burdock (Radix Arctii Lappae), dandelion(Radix Traxaci), elecampane (Radix Inulae), echinacea tea and peppermint were produced by ALIN Company, Alino village, Samokov, Bulgaria. Coltsfoots leaves (Farfara folium) were produced by Thalloderma Ltd., Varna, Bulgaria. Rose hip fruits and thyme leaves were produced by Bioprogramme Ltd, Bulgaria. The plant material was finely ground, kept in closely tight containers and used for further analysis.

\section{Preparation of the extract}

The infusions were prepared as it was described by producer of herbal products. In brief a paper bag $(1 \mathrm{~g})$ of rosehip, thyme, mint, echinacea ( $2 \mathrm{~g}$ ) was poured with $250 \mathrm{ml}$ boiling water and was left for 3-5 min. Coltsfoots leaves $(2 \mathrm{~g})$ was pour with $200 \mathrm{ml}$ boiling water and was left for 1 hour. Dandelion and burdock roots were infused with $500 \mathrm{ml}$ water for $10 \mathrm{~min}$, while 7 g elecampane roots were left with boiling water for $5 \mathrm{~min}$. Microwave-assisted extraction (MAE) was performed in a microwave oven CROWN with $700 \mathrm{~W}$ power and frequency 2450 
$\mathrm{MHz}$ for $5 \mathrm{~min}$ at maximum power $700 \mathrm{~W}$. The extraction was performed in the same water to solid ratio as described above.

\section{Determination of total phenolic content}

The total phenolic content (TPC) was determined using the Folin-Ciocalteu's reagent according to Stintzing et al. (2005) with some modification. Basically, $0.2 \mathrm{ml}$ herbal extract was mixed with $1 \mathrm{ml}$ Folin-Ciocalteu reagent diluted five times and $0.8 \mathrm{~mL} \mathrm{7.5 \%} \mathrm{Na}_{2} \mathrm{CO}_{3}$ was added. After $20 \mathrm{~min}$, the absorption was measured at $765 \mathrm{~nm}$ against a blank sample. The results were expressed in mg equivalent of gallic acid (GAE) $\mathrm{g}^{-1} \mathrm{dw}$, according to a calibration curve; built in range of $0.02-0.10 \mathrm{mg}$.

\section{Determination of total flavonoids content}

The total flavonoids content was determinated by $\mathrm{Al}\left(\mathrm{NO}_{3}\right)_{3}$ reagent. The absorbance was measured at $415 \mathrm{~nm}$. The results were presented as mg equivalents quercetin (QE) per $\mathrm{g} \mathrm{dw}$ according to the calibration curve with quercetin as a standard (Ivanov et al., 2014).

\section{The DPPH radical-scavenging ability}

Each herbal extract $(0.15 \mathrm{ml})$ was mixed with $2.85 \mathrm{ml}$ freshly prepared $0.1 \mathrm{mM}$ solution of DPPH in methanol. The reduction of absorbance at $517 \mathrm{~nm}$ was measured by spectrophotometer in comparison to the blank containing methanol. A standard curve was built with Trolox. The results were expressed in $\mathrm{mM}$ Trolox ${ }^{\circledR}$ equivalents (TE) $\mathrm{g}^{-1} \mathrm{dw}$ (Ivanov et al., 2014).

\section{Spectrophotometric determination of total fructans}

The fructans content in water extracts expressed as fructose equivalent was defined spectrophotometrically by resorcinol-thiourea reagent (Petkova and Denev, 2012). Hundred microliters extract were mixed with $100 \mu \mathrm{L}$ resorcinol $(1 \%$ ethanol solution), $100 \mu \mathrm{L}$ thiourea $(0.1 \%$ ethanol solution), $800 \mu \mathrm{L} 95 \%$ ethanol and $900 \mu \mathrm{L} \mathrm{HCl}$ and heated $8 \mathrm{~min}$ at $80^{\circ} \mathrm{C}$, cooled and filled with water until $10 \mathrm{~mL}$. Then the absorbance was measure at $480 \mathrm{~nm}$ against a blank sample.

\section{HPLC-RID analysis of sugars, fructooligosacharides and inulin}

The sugars, FOSs and inulin content extracts were analyzed by HPLC-RID method. Chromatographic separationwas performed on HPLC Elite Chrome Hitachi, coupled refractive index detector Chromaster 5450 and a column Shodex ${ }^{\circledR}$ Sugar $\mathrm{SP} 0810\left(300 \mathrm{~mm} \times 8.0 \mathrm{~mm}\right.$ i.d.) with $\mathrm{Pb}^{2+}$ and a guard column Shodex SP - G $(5 \mu \mathrm{m}, 6 \times 50 \mathrm{~mm})$ operating at $85^{\circ} \mathrm{C}$. The mobile phase was distilled water with a flow rate $1.0 \mathrm{~mL} \mathrm{~min}^{-1}$ and the injection volume was $20 \mu \mathrm{L}$ (Petkova et al., 2014).

\section{Statistical analysis}

The presented results were average from two independent experiments carried out in triplicates. The data were expressed as mean \pm SD and statistically analyzed using MS Excel software.

\section{RESULTS AND DISCUSSION}

In this study the infusion and microwave water extracts from eight medicinal plants from Asteraceae, Rosacea and Labiatae family were investigated for content of total phenolic, total flavonoids, total fructans and antioxidant activity.

\section{Total phenolic content}

The total phenolic content varied in infusion and microwave water extracts from 5.3 to $47.1 \mathrm{mg} \mathrm{GAEg}^{-1} \mathrm{dw}$ (Table 2 ). The highest content was found in thyme extracts, while the lowest TPC was detected in dandelion roots infusions $(5.3 \mathrm{mg}$ GAE $\mathrm{g}^{-1} \mathrm{dw}$ ). Coltsfoots (42.7 $\mathrm{mg}_{\mathrm{GAE} \mathrm{g}}{ }^{-1} \mathrm{dw}$ ), peppermint (37.7 $\mathrm{mg} \mathrm{GAE} \mathrm{g}^{-1} \mathrm{dw}$ ) and roots of great burdock (34.8 $\mathrm{mg} \mathrm{GAE} \mathrm{g}^{-1} \mathrm{dw}$ ) also demonstrated higher levels of phenolic compounds in comparison with other investigated herbal extracts. Two other medicinal plants with significant amount of TFC were rosehip fruits and Echinacea leaves extracts. The total phenolic content in infusions and microwave extracts decreased in the following order: thyme $>$ coltsfoots $>$ peppermint $>$ great burdock $>$ rosehip $>$ Echinacea $>$ elecampane $>$ dandelion.

Table 2: Total phenolic ( $\mathrm{mg} \mathrm{GAE} \mathrm{g}^{-1} \mathrm{dw}$ ) and total flavonoid content (mg QE g $\left.{ }^{-1} \mathrm{dw}\right)$ in medicinal plant.

\begin{tabular}{|c|c|c|c|c|}
\hline \multirow[t]{2}{*}{ Plant } & \multicolumn{2}{|c|}{ Infusion } & \multicolumn{2}{|c|}{ MAE } \\
\hline & TPC & TF & TPC & TF \\
\hline Rosehip (Rosa canina L.) & $26.8 \pm 0.1$ & $2.9 \pm 0.4$ & $30.1 \pm 0.3$ & $3.0 \pm 0.2$ \\
\hline Thyme (Thymus vulgaris L.) & $41.4 \pm 0.6$ & $6.3 \pm 0.3$ & $47.1 \pm 0.2$ & $9.5 \pm 0.4$ \\
\hline Peppermint (Mentha piperita L.) & $35.1 \pm 1.2$ & $12.5 \pm 0.4$ & $37.7 \pm 0.5$ & $12.8 \pm 0.5$ \\
\hline Coltsfoots (Tussilago farfara L.) & $38.5 \pm 1.1$ & $13.1 \pm 0.6$ & $42.7 \pm 0.3$ & $15.0 \pm 1.1$ \\
\hline Dandelion (Taraxacum officinale Web.) & $5.3 \pm 1.0$ & $2.0 \pm 0.5$ & $6.0 \pm 0.6$ & $2.2 \pm 0.4$ \\
\hline Elecampane (Inula helenium L.) & $9.4 \pm 0.1$ & $3.7 \pm 0.3$ & $10.7 \pm 0.1$ & $4.2 \pm 0.2$ \\
\hline Great burdock (Arctium lappa L.) & $34.8 \pm 0.2$ & $13.1 \pm 0.4$ & $32.4 \pm 1.4$ & $15.6 \pm 1.4$ \\
\hline Echinacea (Echinacea purpurea) & $26.7 \pm 0.4$ & $4.1 \pm 0.7$ & $24.1 \pm 1.1$ & $7.4 \pm 0.6$ \\
\hline
\end{tabular}




\section{Total flavonoids content}

Total flavonoids present in the range from 2.0 to $15.6 \mathrm{mg}$ $\mathrm{QEg}^{-1} \mathrm{dw}$. The highest content of flavonoids was found in infusions and extracts of great burdock roots: 13.1 and $15.6 \mathrm{mg}$ $\mathrm{QEg}^{-1} \mathrm{dw}$, respectively. Coltsfoots and peppermint leaves extracts demonstrated also high content of the total flavonoids content. In contrast, the extracts from dandelion and elecampane roots contained the lowest levels -4.2 and $2.2 \mathrm{mg} \mathrm{QEg}^{-1} \mathrm{dw}$. Our results were in an agreement with previous reports that the most common flavonoids were mainly distributed in representatives from Labiatae and Compositae (Asteracea) (Wojdyło et al., 2007, Kolaneva et al., 2016, Petkova et al., 2017) The results from our study were near or less than some previous reports for total phenolic content in Rosa canina L. fruits from Turkish and Bulgarian origins (Demir and Ozcan, 2001; Pironeet al., 2007; Ghazghazi et al., 2010, Ognyanov et al., 2014; Mihaylova et al., 2015) that could be explained by extraction procedure and used solvent. In general, the highest total phenolics and flavonoids content were established in water extracts obtained after microwave irradiation for $5 \mathrm{~min}$. The difference between infusion and microwave-assisted extraction was not so significant. Similar results were obtained for total phenolic and flavonoid content in both extracts for each medicinal plant (Table 2). Echinacea purpurea water extracts showed significantly high content of total phenolic and flavonoids (Table 2) and the antioxidant activity was also high $193.2 \mathrm{mMTE} \mathrm{g}^{-1} \mathrm{dw}$ for MAE and $164.1 \mathrm{mMTEg}^{-1} \mathrm{dw}$, respectively (Fig. 1). This activity could be explained with presence in the aerial parts of E. purpurea of flavonoids $(0.48 \%)$ (quercetin, kaempferol, isorhamnetin and their glycosides and also anthocyanin, but also and free phenolic acids (chicoric, $p$ coumaric, $p$-hydroxybenzoic and protocatechnic acids) (Barnes et $a l ., 2005)$. Our results showed that the total phenols and AOA was higher than the reported previous for $80 \%$ methanol extracts from the same plant (Pietta et al., 1998, Wojdyło et al., 2007). Therefore, the content of bioactive compounds in extracts strongly depends on extracting solvent and technique. Dandelion and elecampane root, as well as thyme water extracts showed higher results for total phenolic content and antioxidant activity in comparison with previous reports for $80 \%$ methanol extracts (Wojdyło et al., 2007). The total flavonoids content of MAE extracts coincided with our previous study with conventional six hours extraction with ethanol and water (Petkova et al., 2015a, Petkova et al., 2015b). Therefore, the application of accelerated extraction procedure reduces significantly the extraction time with 5 hours and $55 \mathrm{sec}$.

\section{Antioxidant activity}

The radical scavenging activity of different medicinal water extracts was tested using methanol solution of the stable free radical DPPH. The results were summarized in Fig. 1. Great difference in antioxidant activity was observed between species. The results for scavenging of DPPH radical were in ther range from $18.4 \pm 0.6$ to $334.1 \pm 0.3 \mathrm{mM} \mathrm{TE} \mathrm{g}^{-1} \mathrm{dw}$. The highest antioxidant activity possessed great burdock $245.12 \mathrm{mM} \mathrm{TE} \mathrm{g}^{-1} \mathrm{dw}$, followed by coltsfoots and peppermint extracts (Fig. 1). The high antioxidant activity of Arctiticum lappa L. could be explained with the presence of caffeic and chlorogenic acid that possesses antioxidant, strong inhibitory effect on herpesvirus (HSV-1, HSV2) and adenovirus (Chanet al., 2011).

- Infusion a Microwave-assisted extraction

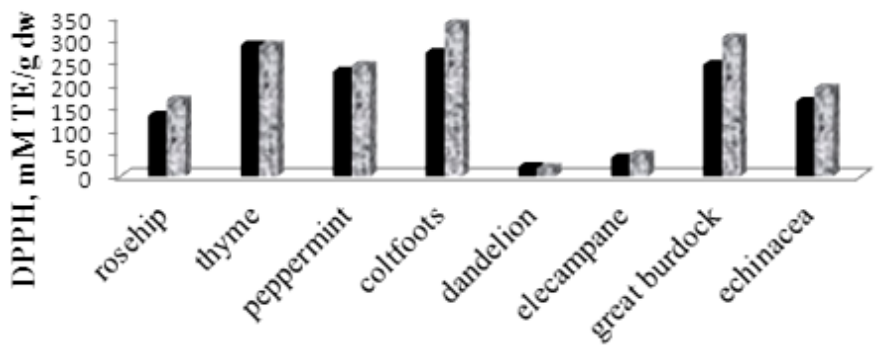

Medicinal Plants

Fig. 1: Antioxidant activity of infusion and water microwave-assisted extracts from selected medicinal plants.

The lowest antioxidant activity possessed dandelion

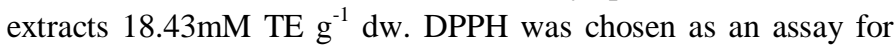
evaluation of antioxidant activity because is quick and simple to be performed. The strongest antioxidant activity was established in the herbal water extracts from microwave extraction. Two representatives from Compositae (Asteracea) (coltfoots and great burdock) and two from Labiate (peppermint and thyme) herbs showed significantly high antioxidant potentials. The high antioxidant activity of coltsfoot could be explained with presence of terpens: arnidol, faradiol, sterols, flavonoids (kaempferol, quercetin and its glycosides, rutin, hiperoside), phenolic acids (ferulic, caffeic, chlorogenic, galic and $p$-hydroxybenzoic acids) (Ivancheva and Stancheva, 2000; Nedelcheva et al., 2015).

\section{Correlation between antioxidant capacity and total phenolic content}

The correlation between total antioxidant capacities obtained by DPPH and total phenolic contents of medicinal plant extracts were presented (Fig. 2A), as well as correlation between DPPH and total flavonoids content (Fig. 2B). The results showed positive linear correlations between total antioxidant activities and total phenolic contents (coefficient of correlation $r^{2}=0.95$ (Table 3).

Table 3: Correlation between total phenolic content (TFC) and antioxidant activities.

\begin{tabular}{ccc} 
& TPC & Flavonoids \\
\hline DPPH & 0.9596 & 0.8000 \\
\hline
\end{tabular}

These results suggested that the total phenolic compounds contributed significantly to the antioxidant activity of the investigated infusions and microwave plant extracts. In addition, similar observations about linear correlation between the content TPC and their antioxidant activity were reported by other researchers (Wojdyło et al., 2007; Krachanova et al., 2010). 

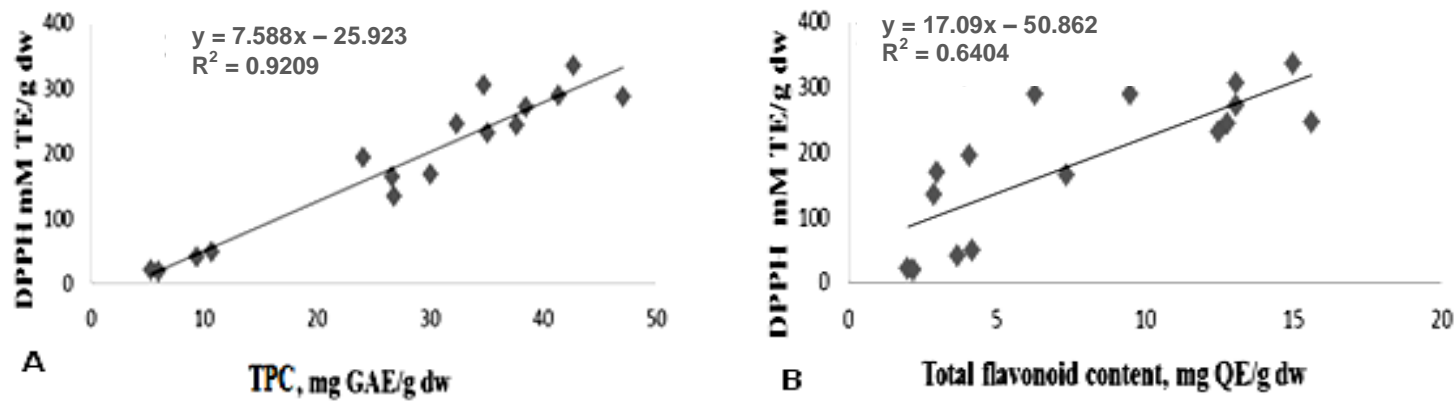

Fig. 2: Linear correlations between DPPH values and total phenolic content $(A)$ values; Coefficient of determination $\left(R^{2}=0.9209\right)$, as well as DPPH values and total flavonoid content (B) for medicinal plant extracts; Coefficient of determination $\left(\mathrm{R}^{2}=0.6404\right)$.

\section{Carbohydrate content}

Fructose, sucrose and fructans were found in detectable content in all extracts from medicinal plants except thyme (Table 4). In general, the carbohydrate content in microwave water extracts was higher than the infusions. Therefore, MAE accelerates extraction of monosaccharides and other carbohydrates in solvents. The highest values were found in elecampane and dandelion roots, where the total fructans dominated significantly. The data obtained

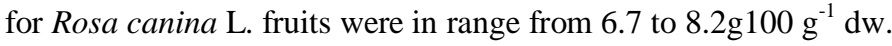
These data were in accordance with previous reports that mature rosehip fruits contained fructose $(6.5 \%)$ and sucrose $(0.5 \%)$ (Pirone et al., 2007; Ognyanov et al., 2014).

Table 4: Carbohydrates content express as fructose equivalent in medicinal plant extracts, g $100 \mathrm{~g}^{-1} \mathrm{dw}$, means $(\mathrm{n}=3)$.

\begin{tabular}{lccc}
\hline Plant & Plant material & Infusion & MAE \\
\hline Rosehip & fruits & $6.7 \pm 0.1^{\mathrm{a}}$ & $8.2 \pm 0.2^{\mathrm{a}}$ \\
Thyme & aerial parts & $\mathrm{n} \cdot \mathrm{d}^{\mathrm{a}}$ & $\mathrm{n} \cdot \mathrm{d}^{\mathrm{a}}$ \\
Peppermint & aerial parts & $1.7 \pm 0.1^{\mathrm{a}}$ & $1.9 \pm 0.1^{\mathrm{a}}$ \\
Coltsfoots & leaves & $2.0 \pm 0.2^{\mathrm{b}}$ & $4.7 \pm 0.2^{\mathrm{b}}$ \\
Dandelion & roots & $27.6 \pm 0.4^{\mathrm{b}}$ & $34.6 \pm 0.6^{\mathrm{b}}$ \\
Elecampane & roots & $41.9 \pm 0.6^{\mathrm{b}}$ & $44.4 \pm 0.4^{\mathrm{b}}$ \\
Burdock & roots & $12.0 \pm 0.2^{\mathrm{b}}$ & $14.5 \pm 0.2^{\mathrm{b}}$ \\
Echinacea & roots & $2.9 \pm 0.1^{\mathrm{b}}$ & $4.7 \pm 0.2^{\mathrm{b}}$ \\
\hline
\end{tabular}

fructose and sucrose; ${ }^{b}$ fructose, sucrose and total fructans (inulin and FOS), n.d -not detected.

More detailed investigation was done for evaluation of fructose, sucrose, inulin and the total fructans. From the obtained results the highest values of inulin $\left(33 \mathrm{~g} 100 \mathrm{~g}^{-1} \mathrm{dw}\right)$ and FOS content were found in elecampane rootsextracts. It is well-known that inulin form chicory and dandelion roots possesses immunomodulation activity and bifidogenic properties (Trojanova et al., 2004).Therefore, its content in herbal extracts is important for human digestion and health. Significant amount of inulin presents in dandelion, elecampane and burdock roots (Fig. 3). Kardošová et al. (2003) and Olennikov and Tankhaeva (2011) reported earlier isolated linear $\beta$-1,2glucofructan from $A$. lapparoots with a degree of polymerization $18-19(\mathrm{Mw}=2.95$ $\mathrm{kDa}$ ) that demonstrated an antitussive effect and a pronounced immunomodulatory activity. Inulin content(4.7 g $\left.100 \mathrm{~g}^{-1} \mathrm{dw}\right)$ in extracts of Arcticum lappa was in agreement with a previous report of Olennikov and Tankhaeva (2011). Moreover, in Bulgarian burdock the levels of inulin and total fructans were lower than Russian representatives, where the content of high molecular inulin can reach up to $30 \%$ (Bagaoutdinova et al., 2001). This could be explained with cold climate conditions, which stimulates accumulation of fructans as storage carbohydrates.

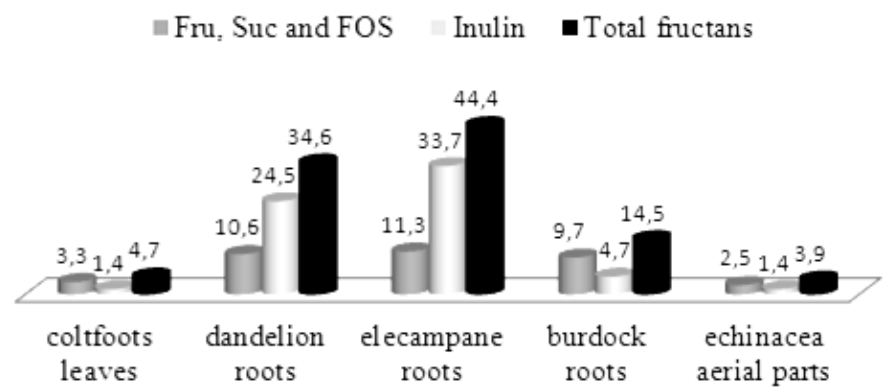

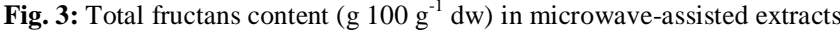
from medicinal plants.

Echinacea and coltsfoots leaves contained fructose, sucrose and FOS (1-kestose and nystose), as inulin in them did not

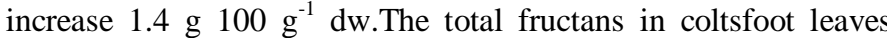
were in small amount in its roots where the content reached up to 17\% (Stoyanov, 1974). Our results for total fructan content $4.7 \mathrm{~g}$ $100 \mathrm{~g}^{-1} \mathrm{dw}$ in Tussilago farfara L. leaves coincided with mentioned data by Holligan et al.(1973).

The roots of medicinal plant Inula helenium L. present a valuable source of fructans from inulin-type, which are classified as soluble dietary fibers (Bagaoutdinova et al., 2001; Petkova et al., 2015b). Contrary to the low total phenolic, total flavonoids and antioxidant activity, root extracts from dandelion and elecampane

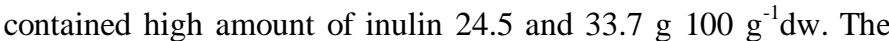
efficiency of microwave-assisted extraction was demonstrated in our earlier research with elecampane roots. The total fructans content in dandelion and elecampane roots extracts coincided with the reported content typical for autumn collected plants $34 \%$ and $44 \%$, respectively (Bagaoutdinova et al., 2001; Petkova et al., 
2012; Petkova et al., 2015a,b). Therefore, the dandelion and elecampane roots are properly harvested when high molecular inulin is accumulated. This is important feature for biological activity, nutritional value and healthy effect of these plants, as potential prebiotics. The prebiotic activity of dandelion oligofructans stimulated the growth of Bifidobacterium cultures (Trojanova et al., 2004).

According to the results from the present work, every cup of microwave extracts prepared from Asteracea representatives contains inulin-type fructans, as follows: Tussilago farfara $-14 \mathrm{mg}$, Taraxacum officinale - $245 \mathrm{mg}$, and Inula helenium 337mg, Arcticum lappa $-47 \mathrm{mg}$ and Echinacea14 mg. The obtained results enrich the information about presence of inulin in herbal infusions and extracts from medicinal plants. Therefore, herbal infusions as well as microwave extracts from these plants present essential source of soluble dietary fiber.

\section{CONCLUSION}

The prepared herbal extracts were evaluated as rich sources of phenolic compounds with high antioxidant activities. Positive correlation between the total phenolic content and antioxidant activity of extracts was established. The infusions and microwave extracts from some of medicinal herbs were evaluated as significant source of inulin with potential prebiotic effect, especially great burdock, elecampane and dandelion roots. One cup of tea from great burdock extract is enough to supply not only the needed content of antioxidants, but also and soluble dietary fiber in human diet. This study provides useful information for consumers and encourages them to consume herbal teas, because of the antioxidant and prebiotic potential of hot drink products and additives with appropriate healthy properties.

\section{Financial support and sponsorship: Nil.}

Conflict of Interests: There are no conflicts of interest.

\section{REFERENCES}

Bagaoutdinova I, Fedoseyeva P,Okoneshnikova F. Fructosecontaining carbohydrates in plants of different families localization and content. Chem. and Comput. Simul. But. Com, 2001; 2(5):13-16.

Barnes J, Anderson LA, Gibbons S,Phillipson JD. Echinacea species (Echinacea angustifolia (DC.) Hell., Echinacea pallida (Nutt.) Nutt. Echinacea purpurea (L.) Moench): a review of their chemistry, pharmacology and clinical properties. J Pharm Pharmacol., 2005; 57: 92954.

Chan Y, Cheng L, Wu J-H, Chan En, Kwan YW, Lee SM.-Y, Leung G, Yu PHF, Chan Sh W. A review of the pharmacological effects of Arctium lappa (burdock). Inflammopharmacol, 2011; 19:245-254.

Demir F, Ozcan M. Chemical and technological properties of rose (Rosa Canina L.) fruits grown wild in Turkey. J Food Engin, 2001; 47: 333-336.

Djeridane A, Yousfi M, Nadjemi B, Boutassouna D, Stocker P,Vidal N. Antioxidant activity of some Algerian medicinalplants extracts containing phenolic compounds. Food Chem. 2006; 97: 654-660.

Ghahfarokhi MG, Barzegar M, Sahari MA, Azizi MH. Enhancement of thermal stability and antioxidant activity of thyme essential oil by encapsulation in chitosan nanoparticles. J Agr Sci Tech. 2016; 18: 1781-1792.

Ghazghazi H, Miguel M, Hasnaoui B, SebeiH, Ksontini M, Figueiredo A, Pedro LG, Barroso JG. Phenols, Essential Oils and Carotenoids of Rosa Caninafrom Tunisia and Their Antioxidant Activities. Afr J Biotechnol. 2010; 9(18): 2709-2716.

Holligan PM, Chen C, Lewis DH. Changes in the carbohydrate composition of leaves of Tussilago farfara during infection by Puccina parum. New Phytol.1973; 72: 947-955.

Huo Y, Shi H, Wang MY, Li XB. Chemical constituents and pharmacological properties of radix Inulae. Pharm., 2008; 63:699-703.

Ivancheva S, Stancheva B. Ethnobotanical inventory of medicinal plants in Bulgaria. J Ethnopharm. 2000; 69(2): 16-172.

Ivanov I, Vrancheva R, Marchev A, Petkova N, Aneva I, Denev P, Georgiev V, Pavlov A. Antioxidant activities and phenolic compounds in Bulgarian Fumaria species. Int J Curr Microbiol App Sci. 2014; 3(2): 296-306.

Ivanova D, Gerova D, Chervenkov T, YankovaT. Polyphenols and antioxidant capacity of Bulgarian medicinal plants. J Ethnopharm. 2005; 96:145-150.

Khadir A, Bendahou M, Benbelaid F, Bellahcene C, Abdelouahid D-E., Museili A, Paollini J, Desjober J., Costa J. Evaluation of the MRSA Sensitivity to essential oils obtained from four algerian medicinal plants. Journal of Applied Pharmaceutical Science. 2013; 3(07): 018-024.

Kardošová A, Ebringerová A, Alföldi J, Nosál'ová G, Fraová S, Híbalová V. A biologically active fructan from the roots of Arctium lappa L., var. Herkules. Biol Macromol. 2003; 33:135-140.

Kolaneva S, Ivanov I, Petkova N, Mihaylova D. Polyphenolic profile and in vitro antioxidant activities of herbal infusions from commercially available Mentha piperita. Proceedings of the XIII National Conference "Natural Science" 2015, 25-27 September, Varna, 2016; 1115 .

Konishi T, Shimada Y, Nagao T, Okabe H, Konoshima T. Antiproliferative sesquiterpene lactones from the roots of Inula helenium. Biol Pharm Bull. 2002; 25: 1370-1372.

Kratchanova M, Denev P, Ciz M, Lojek An,Mihailov At Evaluation of antioxidant activity of medicinal plants containing polyphenol compounds. comparison of two extraction systems.Acta Biochim Pol. 2010; 57(2): 229-234.

Kunle O, Egharevba H, Ahmadu P. Standardization of herbal medicines - a review.Int J Biodiver. Conserv. 2012; 4(3): 101-112.

Manayi A, Vazirian M, Saeidnia S. Echinacea purpurea: Pharmacology, phytochemistry and analysis methods. Pharm Rev. 2015; 9(17): 63-72.

Mihaylova D, Georgieva L, Pavlov A. Antioxidant activity and bioactive compounds of Rosa CaninaL. herbal preparations. Scientific Bulletin. Series F. Biotechnologies. 2015; XIX:160-165.

Miraj S, Keivani Z, Pharmacological effect of Actium lappa: a review study, Pharm Lett. 2016; 8 (9):102-106.

Nedelcheva A,KostovaN, Sidjimov At.Pyrrolizidine alkaloids in Tussilago farfara from Bulgaria, Biotechnol BiotechnolEquip.2015; 29:sup1:S1-S7.

Ognyanov M, Georgiev Y, Denev P, Yanakieva I, Krachanova M. Bioactive compounds and health effects of rose hip fruits. Nauka Dietetika; 2014; 3-4(18):14-27 (on Bulgarian).

Olennikov DN, Tankhaeva LM. A quantitative assay for total fructans in burdock (Arctium spp.) roots. Rus J Bioorg Chem. 2011; 37(7): 893-898

Pamukov P, Ahtardjiev H. 1990. Prirodna apteka.Sofia, Bulgaria,Zemizdat Publisher (on Bulgarian)

Pawlaczyk I, Czerchawski L, Pilecki W, Lamer-Zarawaska E,Gancarz R. Polyphenolic-polysaccharide compounds from selected medicinal plants of Asteraceae and Rosaceae families: chemical characterization and blood anticoagulant activity. Carbohydr Polym. 2009; 77: $568-575$

Petkova N, Denev P. 2012. Extractionanddetermination of fructans (oligofructoses and inulin). Proceeding papers of 9th conference 
"Ecology and Health" Academic press of Agricultural university, Plovdiv, Bulgaria, 399-404 (on Bulgarian).

Petkova N, Vrancheva R, Denev P, Ivanov I, Pavlov A. HPLCRID method for determination of inulin and fructooligo-sacharides. ASN. 2014; 1:99-107.

Petkova N, Ivanov I., Topchieva St, Denev P, Pavlov A. Biologically active substances and in vitro antioxidant activity of different extracts from dandelion (Taraxacum officinale) roots. Scientific Bull. Series F. Biotechnologies. 2015a; XIX: 190-197.

Petkova N, Vrancheva R, Mihaylova D, Ivanov I, Pavlov A, Denev P. Antioxidant activity and fructan content in root extracts from elecampane (Inula helenium L.). J Bio Sci Biotechnol. 2015b; 4(1): 101107.

Petkova N, Ivanov I, VranchevaR, Denev P, Pavlov At. Ultrasound and microwave-assisted extraction of elecampane (Inula helenium) roots. Nat Prod Commun.2017; 12(2):171-174.

Pietta P, Simonetti P, Mauri P. Antioxidant activity of selected medicinal plants. J Agric Food Chem. 1998; 46:4487-4490.

Pirone BN, Ochoa MR, Alicia G, De Michelis, A. Chemical characterization and evolution of ascorbic acid concentration during dehydration of rosehip (Rosa eglanteria) fruits. Am. Journal of Food Techn., 2007; 2(5):377-387.

Schütz K, Muks Er, Carle R, Schieber A. Separation and quantification of inulin in selected artichoke (Cynara ScolymusL.) cultivars and dandelion (Taraxacum officinale Web ex Wigg.) roots by high-performance anion-exchange chromatography with pulsed amperometric detection. Biomed Chrom. 2006; 20:1295-2006.

Stintzing F, Nerbach K, Mosshammer M, Carle R, Yi W, Sellappan S, AcohC, Bunch R, Felker P. Color, betalain pattern, and antioxidant properties of cactus pear (Opuntia Spp.) clones. J Agric Food Chem. 2005; 53(2):442-451.
Stojakowska A, Michalska K, Malarz J. Simultaneous quantification of eudesmanolides and thymol derivatives from tissuesof Inula heleniumand I. Royleanaby reversed-phase high-performance liquid chromatography. Phytochem Anal.2006;17:157-161.

Stoyanov N. 1973. Nashite lekarstveni rasteniya - Part II., Sofia, Bulgaria, Nauka I izkustvo Publisher (on Bulgarian)

Taneva I, Petkova N, Dimov I, Ivanov I, Denev P. Characterization of rose hip (Rosa canina $\mathrm{L}$.) fruits extracts and evaluation of their in vitro antioxidant activity. J Pharmacogn Phytochem.2016; 5:3538 .

Trojanova I, Rada V, Koko`ska L,Vlkov'a E. The bifidogenic effect of Taraxacum officinale root. Fitoterapia. 2004; 75:760-763.

Wojdyło A, Oszmianski J, Czemerys R. Antioxidant activity and phenolic compounds in 32 selected herbs. Food Chem. 2007; 105: 940-949.

\section{How to cite this article:}

Petkova N, Ivanova L, Filova G, Ivanov I, Denev P. Antioxidants and carbohydrate content in infusions and microwave extracts from eight medicinal plants. J App Pharm Sci, 2017; 7 (10): 055-061. 